\title{
On the tension-tension fatigue behaviour of a carbon reinforced thermoplastic part I: limitations of the ASTM D3039/D3479 standard
}

\author{
I. De Baere ${ }^{1}$, W. Van Paepegem ${ }^{1}$, M. Quaresimin ${ }^{2}$ and J. Degrieck $^{1}$ \\ ${ }^{1}$ Department of Materials Science and Engineering, Faculty of Engineering, Ghent University. \\ Sint-Pietersnieuwstraat 41, B-9000 Gent, Belgium. \\ ${ }^{2}$ Department of Management and Engineering, University of Padova. Str. San Nicola 3 \\ 36100 Vicenza, Italy
}

E-mail: Ives.DeBaere@UGent.be

\begin{abstract}
Investigating the fatigue behaviour of a material often requires a lot of experiments in order to have statistically valid results. However, the number of successful fatigue experiments, meaning tab failure did not occur, can be significantly smaller than the total number of experiments.

This manuscript studies the fatigue behaviour of a carbon fabric reinforced PPS using the specimen geometry proposed by the ASTM D3479/D3479M standard. As it turns out, all specimens failed in the tabbed section, meaning that fatigue life may be significantly underestimated and that the proposed geometry needs for improvement.

Therefore, the main emphasis in this manuscript lies on the stiffness degradation and the permanent deformation of the material, rather than on the number of cycles till failure. It may be concluded that for the $\left[\left(0^{\circ}, 90^{\circ}\right)\right]_{4 \mathrm{~s}}$ stacking sequence the material does not show significant stiffness reduction and that only limited permanent deformation is present. Furthermore, the material shows very brittle failure behaviour and the stress-span between infinite fatigue life and failure in a few dozen cycles is very narrow.
\end{abstract}

\section{Introduction}

Investigating the fatigue behaviour of a material is often a very long-lasting and cumbersome procedure. Not only do some of the experiments last very long, in most cases the scatter on the results is fairly large, meaning that most experiments need to be repeated a number of times in order to achieve statistically significant results.

However, one event may happen quite regularly, can be unexpected but compromises the fatigue lifetime data, namely tab failure. The ASTM D3479/D3479M - 96(2007) 'Standard Test Method for Tension-Tension Fatigue of Polymer Matrix Composite Materials' mentions that 'premature failure of the specimen in the tab region is common in tension-tension fatigue testing...' and that 'a combination of tab material, tab length and adhesive that minimizes tab failures' should be found using a set of preliminary fatigue tests. If tab failure happens occasionally, then it is not really a problem, but if this optimal end tab configuration cannot be found, or does not exist, then it is very hard to obtain valid fatigue lifetime results.

In this manuscript, the tension-tension fatigue behaviour of a carbon fabric reinforced thermoplastic, namely polyphenylene sulphide, will be assessed using the rectangular 
specimen geometry, as imposed by the ASTM D3479/D3479M Standard. However, due to the nature of this material, tab failure is likely to occur [1]. It will be attempted to find the optimal end tab configuration, but nevertheless, not too much attention will be given to the number of cycles till failure, since this will always be an underestimation in the case of tab failure. Therefore, the behaviour throughout the fatigue life will be observed more closely in this part of the study. In the second part of this study [2], some improvements to the geometry will be suggested and their effects on the fatigue behaviour will be commented on.

Throughout the fatigue lifetime, damage can take many forms in fibre-reinforced composites [3,4,5]: (i) matrix cracks, (ii) fibre-matrix interface failure, (iii) fibre pull-out, (iv) delaminations, (v) fibre fracture. This damage affects the value of the elastic properties at an early stage. Especially in fatigue, the damage initiation phase can cause a pronounced drop of the elastic modulus of 5 to $10 \%$. In the next damage propagation phase, the stiffness continues to decrease gradually, ranging from a few percent for unidirectionally reinforced carbon composites to several tens of percents for multidirectional glass laminates $[6,7,8,9,10,11,12,13]$. Furthermore, most onedimensional damage models for fibre-reinforced composites only account for the effect of damage on the stiffness [5, 13, 14, 15, 16, 17, 18, 19, 20, 21, 22, 23, 24]. As such, the main focus in the fatigue experiments described here is on the expected stiffness degradation and permanent deformation.

In the next paragraph, the used material is discussed.

\section{Materials and Methods}

\subsection{Composite Material}

The material under study was a carbon fibre-reinforced polyphenylene sulphide (PPS), called CETEX and is supplied to us by Ten Cate Advanced Composites. The fibre type is the carbon fibre T300J 3K and the weaving pattern is a 5-harness satin weave with a mass per surface unit of $286 \mathrm{~g} / \mathrm{m}^{2}$. The 5-harness satin weave is a fabric with high strength in both directions and excellent bending properties.

The carbon PPS plates were hot pressed, only one stacking sequence was used for this study, namely a $\left[\left(0^{\circ}, 90^{\circ}\right)\right]_{4 s}$ where $\left(0^{\circ}, 90^{\circ}\right)$ represents one layer of fabric.

The in-plane elastic properties of the individual carbon PPS lamina were determined by the dynamic modulus identification method as described in [25] and are listed in Table 1. These values were also confirmed by meso-scale modelling [26, 27].

Table 1 In-plane elastic properties of the individual carbon/PPS lamina (dynamic modulus identification method).

\begin{tabular}{lcc}
\hline $\mathrm{E}_{11}$ & 56.0 & $\mathrm{GPa}$ \\
$\mathrm{E}_{22}$ & 57.0 & $\mathrm{GPa}$ \\
$\mathrm{v}_{12}$ & 0.033 & - \\
$\mathrm{G}_{12}$ & 4.175 & $\mathrm{GPa}$ \\
\hline
\end{tabular}

The tensile strength properties were determined at the Technical University of Delft and are listed in Table 2.

Table 2 Tensile strength properties of the individual carbon/PPS lamina (Mechanical testing at TUDelft).

\begin{tabular}{lll}
\hline $\mathrm{X}_{\mathrm{T}}$ & $734.0 \quad \mathrm{MPa}$ \\
\hline
\end{tabular}




\begin{tabular}{lcc}
\hline$\varepsilon_{11}$ ult & 0.011 & - \\
$\mathrm{Y}_{\mathrm{T}}$ & 754.0 & $\mathrm{MPa}$ \\
$\varepsilon_{22}{ }_{\text {ult }}$ & 0.013 & - \\
$\mathrm{S}_{\mathrm{T}}$ & 110.0 & $\mathrm{MPa}$ \\
\hline
\end{tabular}

The test coupons were sawn with a water-cooled diamond saw. The dimensions of the coupons are shown in Figure 1 and are according to the D3479/D3479M - 96 (2007) 'Standard Test Method for Tension-Tension Fatigue of Polymer Matrix Composite Materials' and D3039/D3039M-08 'Standard Test Method for Tensile Properties of Polymer Matrix Composite Materials'.

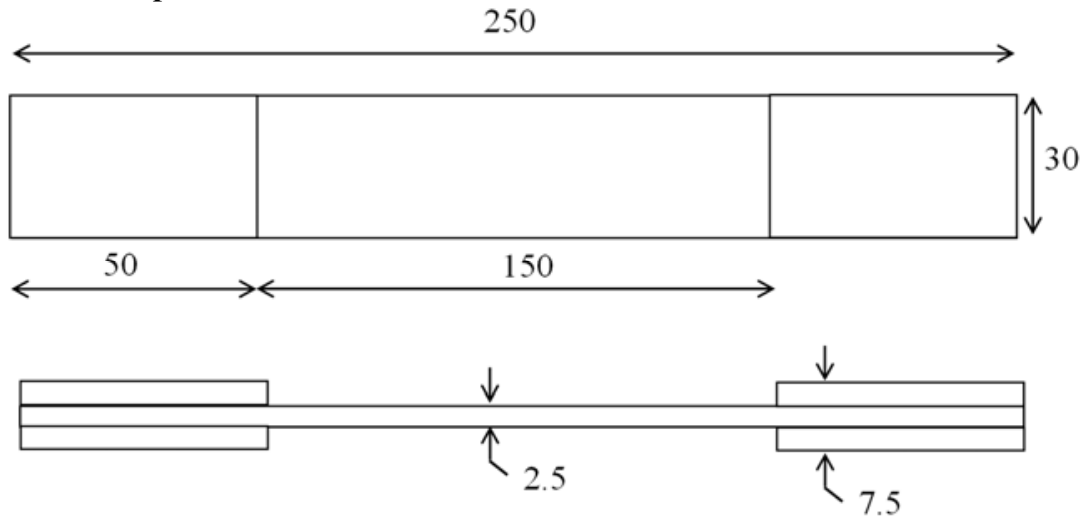

Figure 1 Dimensions of the used tensile coupon for the tension-tension fatigue tests, equipped with straight-end tabs of $\left[\left(0^{\circ}, 90^{\circ}\right)\right]_{4 \mathrm{~s}}$ carbon/PPS [1].

\subsection{Equipment}

All tensile tests were performed on a servo-hydraulic INSTRON 8801 tensile testing machine with a FastTrack 8800 digital controller and a load cell of $\pm 100 \mathrm{kN}$. All fatigue experiments were done in load-control.

For the registration of the tensile data, a combination of a National Instruments 6251 data acquisition card for USB and the SCB-68 pin shielded connector was used. The load, displacement and strain, given by the FastTrack controller were sampled on the same time basis.

\section{Experiments and Discussion}

\subsection{Quasi-static experiments till failure}

All quasi-static tests were performed displacement-controlled with a displacement speed of $2 \mathrm{~mm} / \mathrm{min}$. Figure 2 shows the stress-strain relationship for two such experiments. The geometry of Figure 1 was used, but with aluminium tabs of $1 \mathrm{~mm}$ thickness. It can be seen that a linear behaviour till failure is present, although it should be remarked that failure occurred inside the end-tabs, meaning that the failure strength is underestimated. Therefore, before starting with fatigue experiments, a suitable combination of end tab material, geometry (chamfered or straight) and adhesive must be determined. 


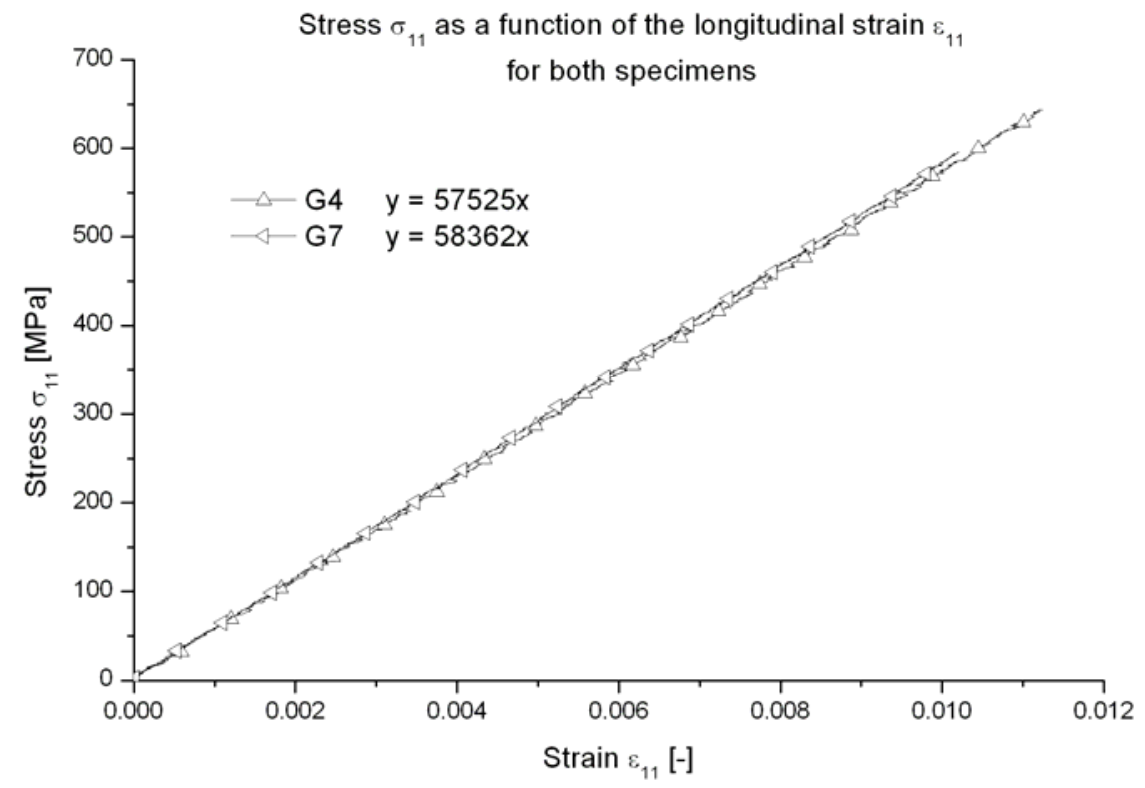

Figure 2 Longitudinal stress as function of the longitudinal strain for two specimens

In order to do so, several experiments were performed; different kinds of tab material, tab geometry, adhesive and surface preparation were tested.

The different types of fracture that occurred are depicted in Figure 3; they are illustrated for chamfered tabs, but the meaning remains the same in the case of straight tabs.

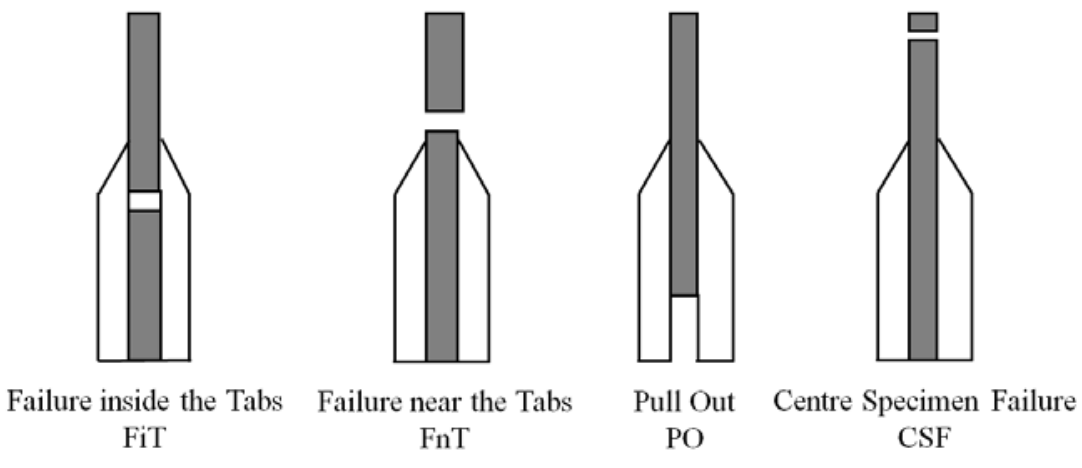

Figure 3 Different types of failure that occurred during tensile and compressive testing.

To limit the length of the tabs, a chamfering angle of $12^{\circ}$ is used. The length of the tabs is $60 \mathrm{~mm}$ and the width is $30 \mathrm{~mm}$. All significant preliminary experiments that were performed are listed in Table 3. The stacking sequence for the $250 \mathrm{~mm}$ by $30 \mathrm{~mm}$ tensile coupon was always the same, namely the $\left[\left(0^{\circ}, 90^{\circ}\right)\right]_{4 \mathrm{~s}}$.

Table 3 Performed experiments on bonding the tabs by means of an adhesive.

\begin{tabular}{ccccccc}
\hline Nr. & Tab material & Surface preparation Used adhesive & $\begin{array}{c}\text { Maximum } \\
\text { stress } \\
{[\mathrm{MPa}]}\end{array}$ & $\begin{array}{c}\text { Type of } \\
\text { fracture }\end{array}$ \\
& & & & & \\
1 & Straight aluminium & Sanded + acetone & Loctite 405 & 671 & FiT \\
2 & Straight aluminium & Sanded + acetone & Epofix & 610 & FiT \\
3 & Straight aluminium & Sanded + acetone & Plexus MA425 & 631 & PO \\
4 & Straight glass-epoxy & Sanded + acetone & Loctite 405 & 595 & FnT \\
5 & Straight glass-epoxy & Sanded + acetone & Epofix & 720 & FiT \\
\hline
\end{tabular}




\begin{tabular}{|c|c|c|c|c|c|}
\hline 6 & Straight glass-epoxy & Sanded + acetone & $\begin{array}{l}\text { Hysol EA9394 } \\
\text { and glass beads }\end{array}$ & 601 & FiT \\
\hline 7 & Straight PEI & Sanded + acetone & Hysol EA9394 & 665 & FnT \\
\hline 8 & Straight PEI & Sanded + acetone & $\begin{array}{l}\text { Hysol EA9394 } \\
\text { and glass beads }\end{array}$ & 741 & FnT \\
\hline 9 & Straight PPS & Sanded + acetone & Loctite 405 & 650 & FiT \\
\hline 10 & Straight PPS & Sanded + acetone & $\begin{array}{c}\text { Loctite } \\
\text { superglue } 3\end{array}$ & 740 & FiT \\
\hline 11 & Straight PPS & $\begin{array}{c}\text { Sanded }+ \text { acetone }+ \\
\text { glass-fibres }\end{array}$ & Epofix & 745 & FiT \\
\hline 12 & Chamfered PPS & Sanded + acetone & MMA 300 & 270 & $\mathrm{PO}$ \\
\hline 13 & Chamfered PPS & Sanded + acetone & Plexus MA425 & 323 & $\mathrm{PO}$ \\
\hline 14 & Chamfered PPS & Sanded + acetone & Epofix & 780 & FnT \\
\hline 15 & Chamfered PPS & $\begin{array}{l}\text { Sandblasted + } \\
\text { acetone }\end{array}$ & Loctite 406 & 738 & FiT \\
\hline 16 & Chamfered PPS & $\begin{array}{l}\text { Sandblasted + } \\
\text { acetone }\end{array}$ & Plexus MA420 & 675 & FiT \\
\hline
\end{tabular}

It can already be seen that in all cases mentioned in Table 3, none resulted in an acceptable failure, meaning that failure occurred in (or near) the centre of the specimen. Also, some results proved highly irreproducible, when multiple experiments were performed, only the maximum achieved stress is mentioned in Table 3. As can be noted, the failure stress achieved by TUdelft (Table 2) was also reached for some combinations. Eventually, the best and reproducible results, were obtained with setup 10 , using straight end tabs of the same material, with the same stacking sequence and bonded with Loctite superglue3, although the failure kept occurring inside the end tabs. Therefore, an extensive numerical study was conducted to obtain the best end tab combination for this material and to determine the reason for the end tab failure [1]. From this study, it was concluded that for the given material, straight end tabs with the same stacking sequence yields the best results, but in every case (straight or chamfered tabs, different tab materials, ...) stress concentrations exist underneath the tabs, so with the geometry from the D3479/D3479M - 96 (2007) 'Standard Test Method for TensionTension Fatigue of Polymer Matrix Composite Materials' and D3039/D3039M-00 'Standard Test Method for Tensile Properties of Polymer Matrix Composite Materials' tab failure is very likely to occur for the $\left[\left(0^{\circ}, 90^{\circ}\right)\right]_{4 \mathrm{~s}}$ stacking sequence of the carbon PPS under study. Figure 4 illustrates the occurring longitudinal stress concentration when straight end tabs are used for various end tab materials, the value $R_{A}$ represents the gripping force; for more details, the authors refer to [1]. 


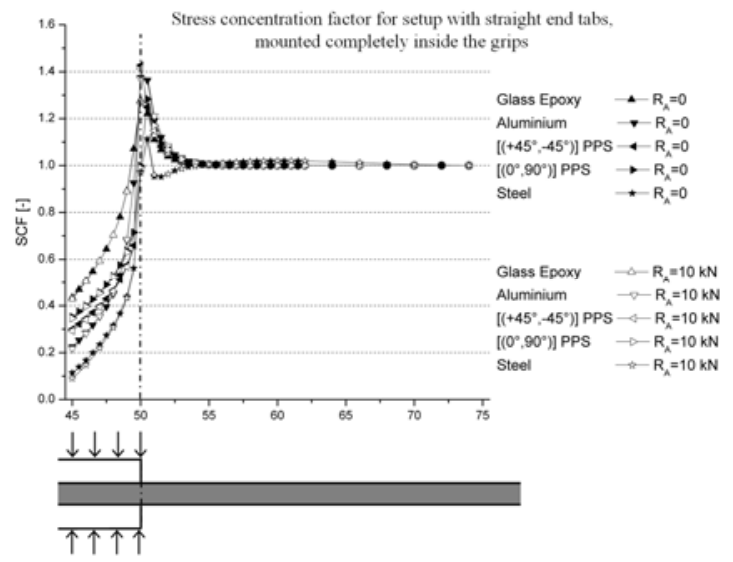

(a) Mounted inside the grips

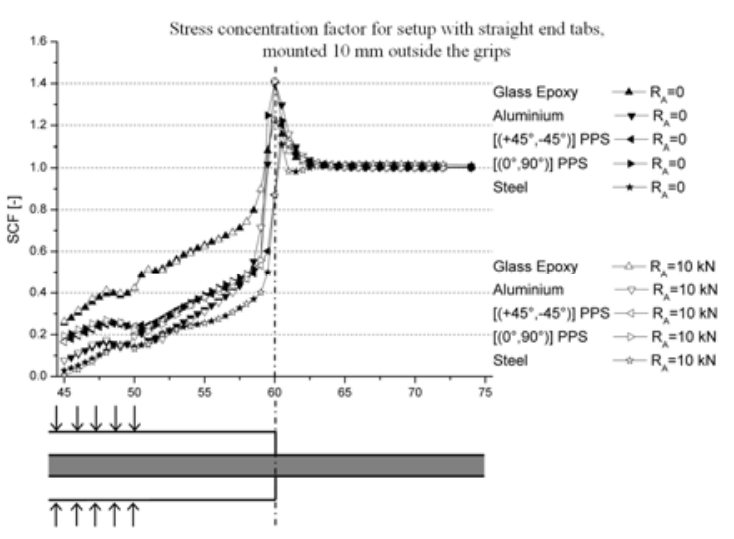

(b) Mounted partially outside the grips

Figure 4 Illustration of the stress concentration factor for the longitudinal stress when straight end tabs are used [1].

It should be mentioned that some of the configurations mentioned in Table 3 were also assessed under fatigue loading conditions, but in general, if a configuration was bad under static conditions, it was even worse under fatigue loading conditions.

\subsection{Fatigue experiments on $\left[\left(0^{\circ}, 90^{\circ}\right)\right]_{4 s}$ specimens}

A first test was done with a maximum stress of $400 \mathrm{MPa}$ at $5 \mathrm{~Hz}$. This stress is about $55 \%$ of the static failure stress and the frequency is chosen as a compromise between the expected heat generation and the duration of the experiment. In order to evaluate the stiffness degradation, the experiment was paused regularly and displacement-controlled quasi-static tests at $2 \mathrm{~mm} / \mathrm{min}$ were performed. However, no real stiffness degradation occured during the test and there was only very limited permanent deformation. It should also be noted that there was no significant change in temperature. The test was stopped after 1,268,688 cycles without failure, or even any visible damage in the specimen, although it should be remarked that the end tabs have debonded. With respect to the 'visible damage', no distinct delaminations or significant transverse cracks were visible. Observation of polished sides of the specimens clearly shows that local damage (matrix cracks) already occurs at lower load levels, as illustrated in Figure 5 where a specimen which was loaded till $400 \mathrm{MPa}$, is depicted. For a more detailed meso-and micro-mechanical study of this material, the authors refer to [26].

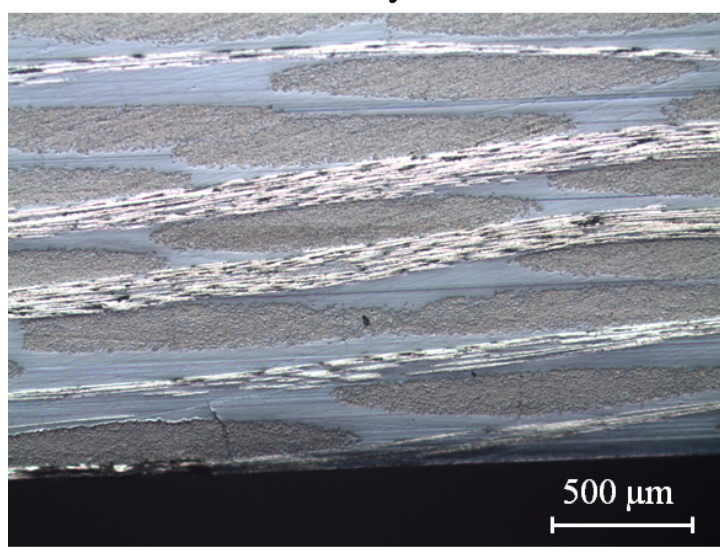

(a) Loaded till $170 \mathrm{MPa}$

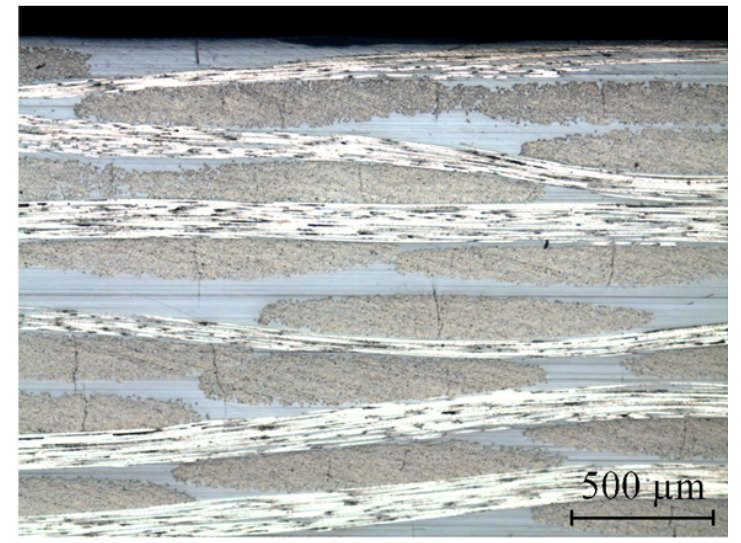

(b) Loaded till $400 \mathrm{MPa}$

Figure 5 Illustration of cracks on a polished specimen, for two different load levels. 
The next experiment had a maximum stress level of $450 \mathrm{MPa}$ also at $5 \mathrm{~Hz}$. Again there was no significant change in temperature nor any real stiffness degradation and only limited permanent deformation. The latter could be derived from both the fatigue data and the intermediate quasi-static experiments. The fatigue experiment was stopped without failure or visible damage after 1,283,421 cycles.

Since the increase of $50 \mathrm{MPa}$ did not yield different results, the maximum stress is now increased to $550 \mathrm{MPa}$. The results of such a test are shown in Figure 6, but again show a trend similar to all previous results. There is no significant temperature change due to fatigue loading, nor does stiffness degradation or permanent deformation occur. The test specimen failed after 1,217,500 cycles and failure occurred in the end tabs, meaning fatigue life is underestimated.

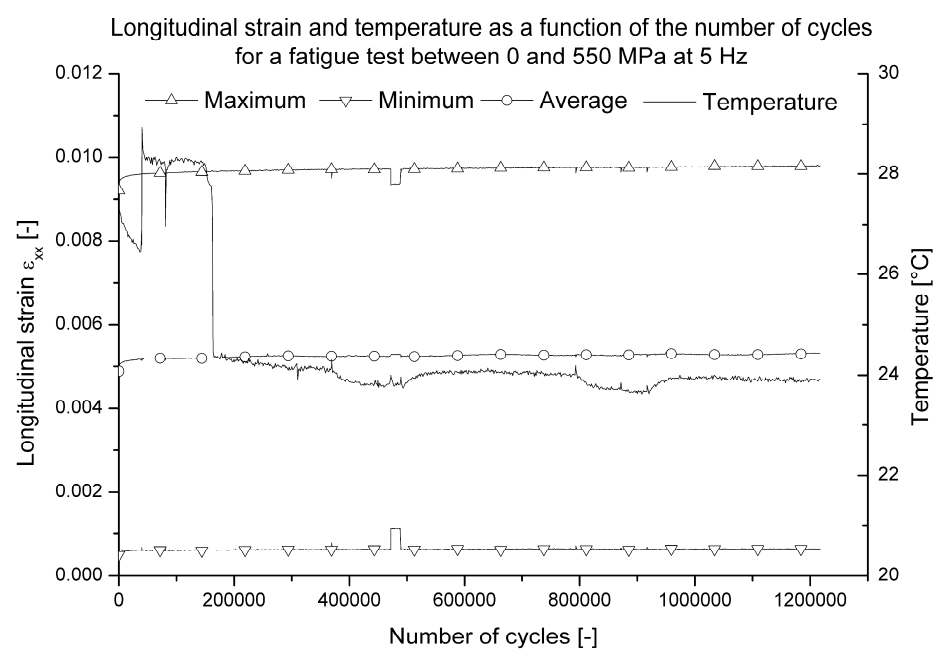

Figure 6 Maximum, minimum and mean value of the strain and the temperature during the $550 \mathrm{MPa}$ @5zz fatigue experiment.

The variations of the temperature are due the changes in the room temperature. The room where the experiments were conducted, has a climate control system but the variations in Figure 6 are within the range of this system. The first peak to $28^{\circ} \mathrm{C}$ was due to a malfunction in the climate system. In general, for all of the uni-axial fatigue experiments, no significant variation in temperature occurred, and all changes can be ascribed to variations in room temperature.

The results of the intermediate quasi-static tests are shown in Figure 7 and indeed no stiffness degradation occurs and only very limited permanent deformation can be seen. It should be noted that the stiffness corresponds well with the values given in Table 1 (which was also the case for all previous experiments). The small deviations are within the normal scatter of the elastic properties of composite materials. Since the same conclusions with respect to stiffness degradation and permanent deformation can be drawn from the evolution of the strain throughout the fatigue experiment, there is no need for performing the intermediate quasi-static experiments for this material. 


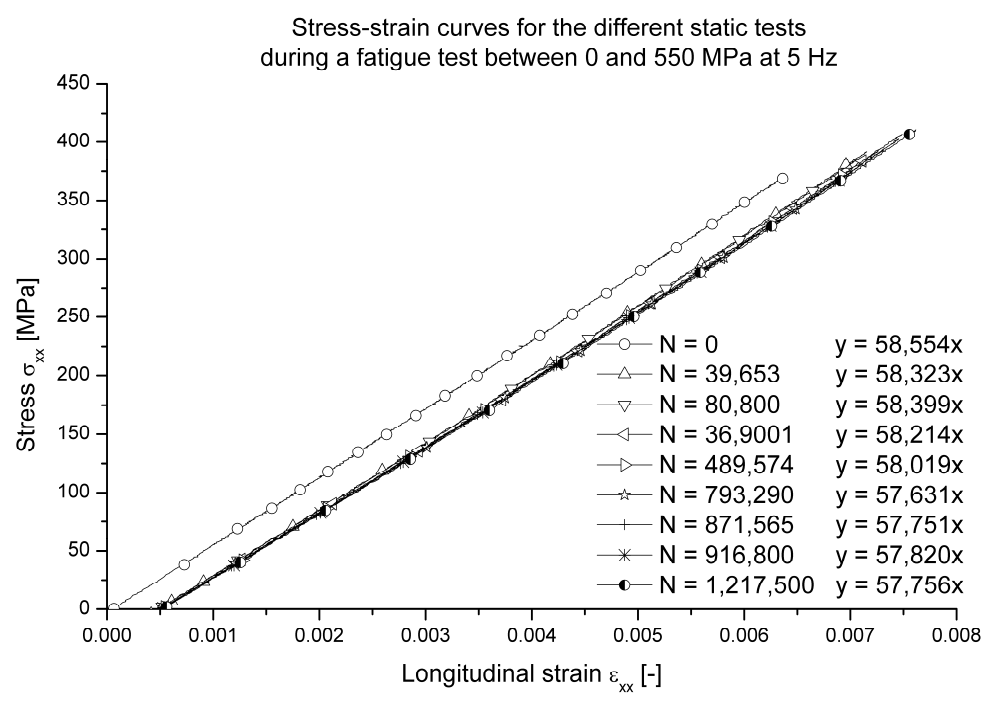

Figure 7 Results for the intermediate quasi-static tests from the $550 \mathrm{MPa}$ @ $5 \mathrm{~Hz}$ test.

When the intermediate quasi-static experiments are observed more closely, it appears that the limited permanent deformation tends to develop early in fatigue life. For a $450 \mathrm{MPa} @ 5 \mathrm{~Hz}$ test, after 41,570 cycles, the static curves were coincident; for the 550 MPa@5Hz test (Figure 7), the same can be said after 39,653 cycles. It should be noted that the number of cycles correspond to the first quasi-static experiment performed during that test. Therefore, it is possible that the static curves may coincide earlier in fatigue life.

Figure 8 shows the longitudinal stress-strain relationship of about sixty cycles during the run-in of a $550 \mathrm{MPa} @ 5 \mathrm{~Hz}$ experiment and as can be seen, the limited permanent deformation tends to develop in these first sixty cycles. This is also the reason why the minimum value of the strain does not start at zero in all fatigue graphics illustrated. A closer observation of the run-in of the other experiments yielded the same conclusion. After a few dozens of cycles, the stress-strain curves coincide.

The derived stiffness during the run-in corresponds well with the values given in Table 1 , although the displacement speed is a lot higher than $2 \mathrm{~mm} / \mathrm{min}$, required for quasistatic testing. As such, it can be concluded that the testing speed does not seem to have an influence on the Young's modulus and this again confirms that there is no need to perform intermediate quasi-static tests for this material.

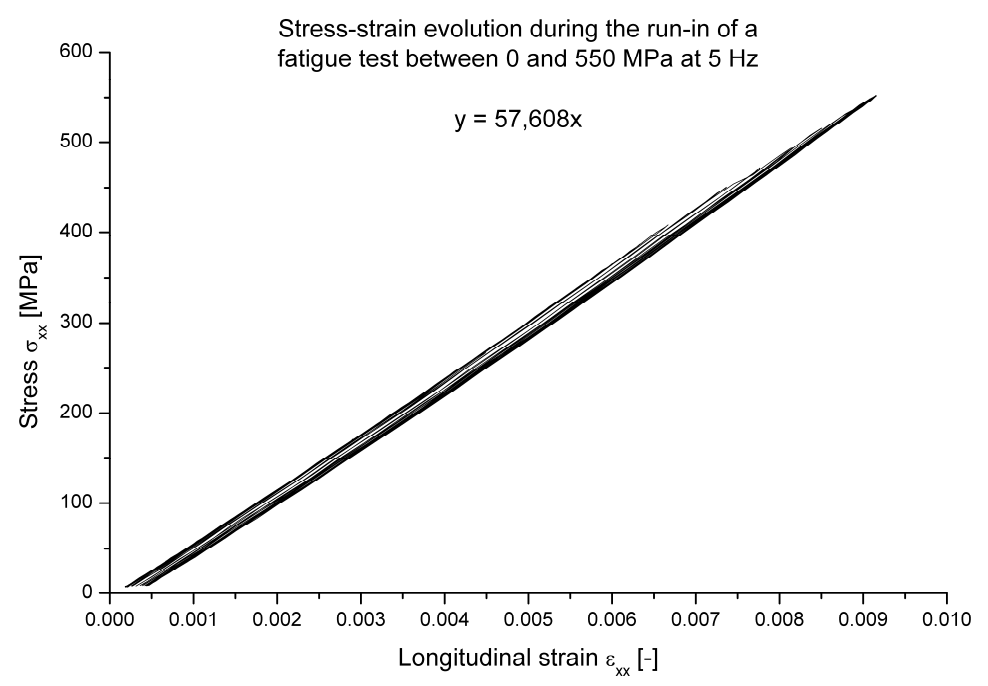

Figure 8 Stress as function of the strain for the run-in of a 550 MPa@5Hz experiment. 
Almost all experiments with higher maximum stress levels of $575 \mathrm{MPa}$ and $600 \mathrm{MPa}$ failed during or soon after the run-in in the tabbed section, so these results are not shown here.

A remark must be made concerning the fatigue tests with $550 \mathrm{MPa}$ as maximum stress level. The experiment showed here failed after about 1.2 million cycles and a few others also survived one million cycles or failed soon afterwards. However, multiple specimens failed very early in the expected fatigue life, due to tab failure, caused by the already mentioned stress concentrations, inherent to the used geometry [1]. Furthermore, the failure of the adhesive layer, causing debonding of the tab also results in failure. The latter causes friction and wear to occur and the generated heat causes the premature failure. Moreover, due to the debonding, the stress concentration shifts to the edge of the debonded zone, since the stress concentration occurs at the edge of this zone (see Figure 4). As such, specimens which fail during or soon after the run in, usually fail just outside the end tabs, whereas specimens which last longer, usually fail inside the end tabs, although this also depends on the quality of the bond. The occurring failures are illustrated in Figure 9.

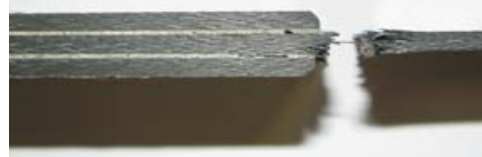

(a) during run-in

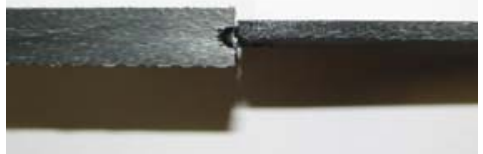

(b) soon after run-in/good bond

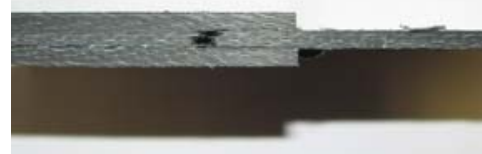

(c) late in fatigue life/bad bond

Figure 9 Overview of the occurring tab failures during fatigue experiments

Therefore, three options are explored: (i) specimens without end tabs; (ii) specimens with welded end tabs and (iii) a lower test frequency, so that less frictional heat is generated. The latter also allows investigating the effect of the frequency on the fatigue behaviour.

The first option always resulted in very early failure inside the grips, due to the stress concentration of the serrated surfaces of the grips. For the second option, the end tabs were fusion bonded to the specimen, using the 'hot-tool' principle [28]. Figure 10 shows a microscopic image of a weld, generated using the 'hot-tool' principle. As can be seen, no voids are present, so that a high mechanical strength is achieved. 


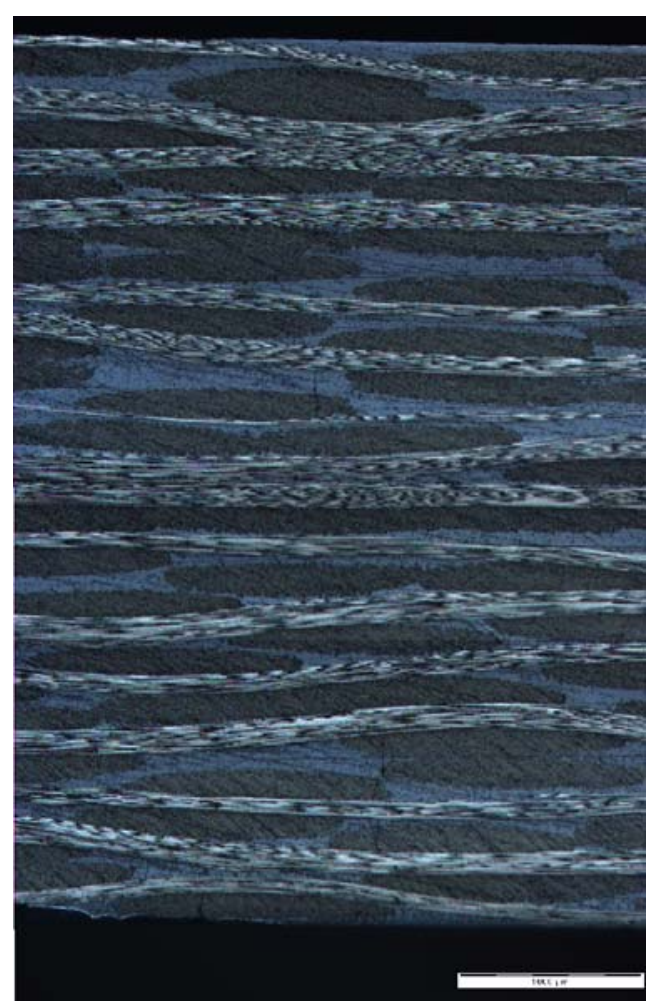

Figure 10 Microscopic view of a welded tab, manufactured by using 'hot-tool' welding

The use of fusion bonded tabs indeed eliminated the friction and wear due to debonding of the tab in early fatigue life and is as such an improvement, but due to the high stress concentrations, the weld also degenerated and failed over a certain length, again leading to friction underneath the tabs. In al test cases, the specimen failed in the end tabs, without any relevant difference in fatigue life value and scatter compared to the specimens with adhesively bonded tabs. Therefore, the third option is investigated more thoroughly.

Figure 11 illustrates the temperature and strain evolution of a $2 \mathrm{~Hz}$ experiment with a maximum stress level of $550 \mathrm{MPa}$. Yet again, there is no significant stiffness reduction, nor permanent deformation. The specimen failed after 1,898,997 cycles in the vicinity of the end tabs, meaning the lifetime is underestimated, but besides the fracture, no visible (global) damage could be detected.

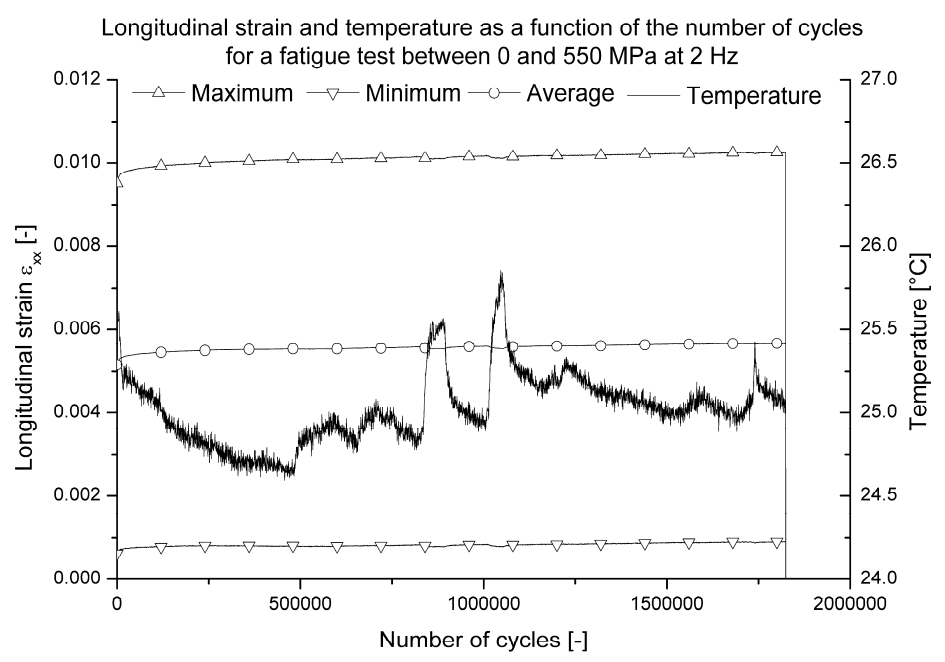


Figure 11 Maximum, minimum and mean value of the strain and the temperature during the $550 \mathrm{MPa} @ 2 \mathrm{~Hz}$ fatigue experiment.

Again it appears that the permanent deformation occurs during the first cycles. This was confirmed during the run-in of this experiment; most of the permanent deformation indeed forms during the first thirty cycles. The derived stiffness corresponds well with the values determined with quasi-static testing.

Various experiments were performed at this loading frequency, but the same conclusions as for the $5 \mathrm{~Hz}$ test frequency could be made with respect to the lifetime. For $\sigma_{\max }$ equal to $550 \mathrm{MPa}$, a number of specimens survive over one million cycles, but multiple specimens fail very early, due to frictional heating in the tabs. For a higher maximum stress level, the specimen fails during or soon after the run-in.

Figure 12 summarises all successful fatigue tests, meaning that the specimen did not fail prematurely with respect to other test results. However, since all of these specimens still failed in the section underneath the tab or very close to the end tab, these results need to be interpreted as a lower boundary for fatigue life.

It can be noticed that the stress-span between infinite fatigue life and failure in a few dozen cycles is very narrow. For a maximum stress lower than $550 \mathrm{MPa}$, the material has a lifetime well over one million cycles, which may be considered infinite, whereas for values higher than $600 \mathrm{MPa}$, the specimen fails after a few dozen cycles.

For more fatigue results, the authors refer to [29, 2].

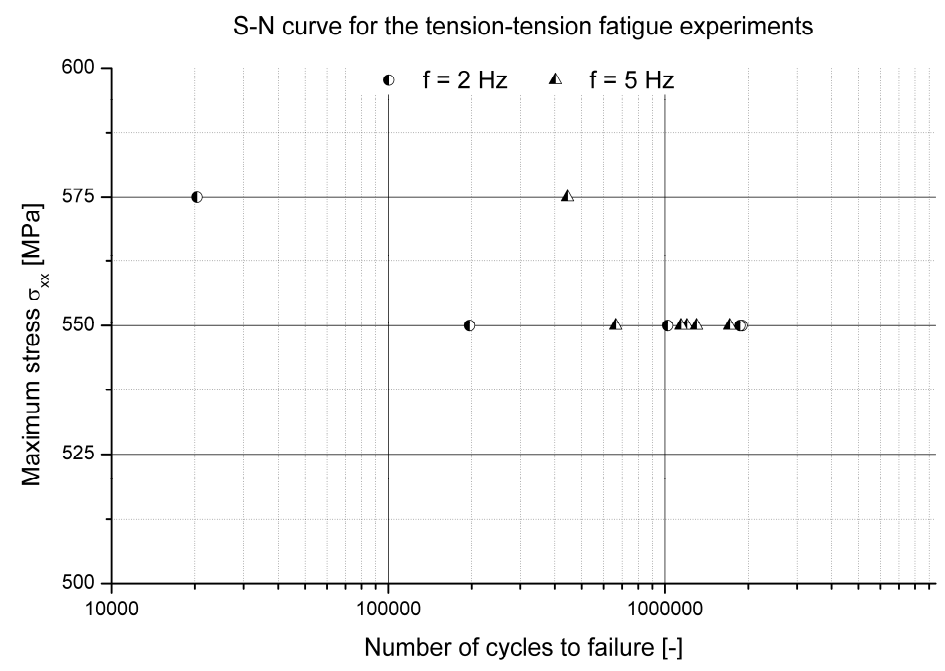

Figure 12 S-N curve for all uni-axial fatigue experiments conducted for this part of the research.

\subsection{Fatigue experiments on $\left[\left(+45^{\circ},-45^{\circ}\right)\right]_{4 s}$ specimens}

In a previous study [30], the fatigue behaviour under shear loads has already been discussed. For the tension-tension fatigue tests, the geometry proposed by the D3039/D3039M-00 standard was also considered for specimens with a $\left[\left(+45^{\circ},-45^{\circ}\right)\right]_{4 \mathrm{~s}}$ stacking sequence. For this study, the outcome was quite different and tab failure never occurred. However, another peculiar phenomenon presented itself. Because of heat generation due to shear loading, the temperature of the specimen rose higher than the softening temperature of the polyphenylene sulphide $\left(90{ }^{\circ} \mathrm{C}\right)$. Under influence of the tensile load, the fibres started to realign themselves along the loading direction, causing the specimen to change geometry. In Figure 13 the specimen N2, on which a 0-50 MPa, 
$2 \mathrm{~Hz}$ fatigue experiment was done, can be compared with another specimen which is still to be tested, but with the same dimensions as specimen N2 had before testing.

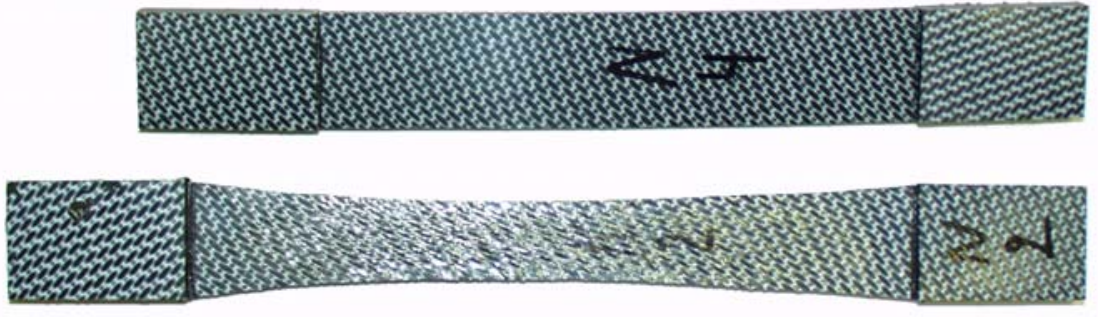

Figure 13 Un-deformed (top) and deformed (bottom) [(45, $\left.\left.-45^{\circ}\right)\right]_{4 \mathrm{~s}}$ specimen [30].

The realigning of the fibres can be seen in a detailed image of specimen N2 (see Figure 14)

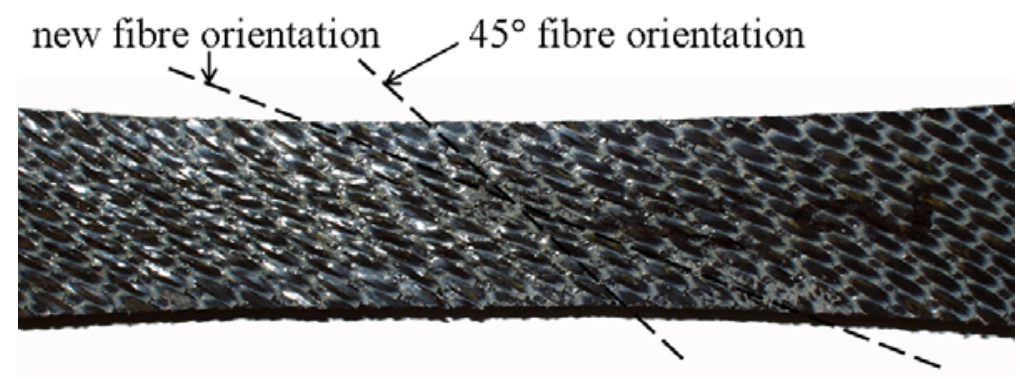

Figure 14 Illustration of the change in fibre orientation due to the softening of the matrix [30].

Therefore, it may be interesting to assess whether a dogbone shape, which is quite commonly used for pure plastics and metals, would yield different fatigue results for the $\left[\left(0^{\circ}, 90^{\circ}\right)\right]_{4 s}$ stacking sequence of the material under study. This, however, will be described in part II of this study [2].

\section{Conclusions}

This paper assessed the use of the D3479/D3479M - 96 (2007) 'Standard Test Method for Tension-Tension Fatigue of Polymer Matrix Composite Materials' and D3039/D3039M-08 'Standard Test Method for Tensile Properties of Polymer Matrix Composite Materials' for tension-tension fatigue experiments on a carbon fabric reinforced polyphenylene sulphide. Although an extensive test program was considered to obtain the best adhesive and end-tab geometry, failure almost always occurred underneath the end-tabs for the $\left[\left(0^{\circ}, 90^{\circ}\right)\right]_{4 \mathrm{~s}}$ specimens. Therefore, the fatigue (lifetime) results should be interpreted with caution, since the tab failure inherently implies an underestimation of fatigue lifetime. Taking this into consideration, it may be concluded that the stiffness shows no degradation; with respect to the permanent elongation, it may be said that almost no permanent deformation occurs because of the fatigue loads. Only during the first fifty cycles or so, a limited amount of permanent deformation is formed. Therefore, it can be said that the material itself has a very brittle behaviour. Also, it breaks very sudden without any visible or audible cracks before failure. Furthermore, the stress-span between infinite fatigue life and failure in a few dozen cycles is very narrow, about $50 \mathrm{MPa}$.

For the fatigue experiments on the $\left[\left(+45^{\circ},-45^{\circ}\right)\right]_{4 s}$ stacking sequence, considered in earlier studies, failure never occurred underneath the end tabs, but the shape of the specimen changed from the rectangle, as prescribed by the standard, to a dogbone like shape, as result from heat generation due to shear loadings. As such, a dogbone like 
shape is considered in part II of this study, to validate whether such geometry produces more reliable fatigue results.

\section{Acknowledgements}

The authors would like to thank Ten Cate Advanced Composites for supplying the material and they gratefully acknowledge the finance through a grant of the Fund for Scientific Research - Flanders (F.W.O.).

\section{References}

[1] De Baere I., Van Paepegem W. and Degrieck J., On the design of end tabs for quasi-static and fatigue testing of fibre-reinforced composites. Polymer Composites Volume 30, Issue 4, Pages 381-390, April 2009.

[2] De Baere I., Van Paepegem W. Hochard C. and Degrieck J On the tension-tension fatigue behaviour of a carbon reinforced thermoplastic part II: A dumbbell-shaped specimen.

Polymer Testing, Volume 30, Issue 6, September 2011, Pages 663-672

[3] Mallick, P.K. (1997). Composites Engineering Handbook. New York, Marcel Dekker Inc.

[4] Herakovich, C.T. (1998). Mechanics of fibrous composites. New York, John Wiley \& Sons, Inc.

[5] Talreja, R. Damage and fatigue in composites - A personal account. Composite Science and Technology 68 (13)pages: 2585-2591 (2008)

[6] Schulte, K., Baron, Ch., Neubert, H., Bader, M.G. , Boniface, L., Wevers, M., Verpoest, I. and de Charentenay, F.X. (1985). Damage development in carbon fibre epoxy laminates : cyclic loading. In : Proceedings of the MRS-symposium "Advanced Materials for Transport", November 1985, Strassbourg, 8 p.

[7] Schulte, K., Reese, E. and Chou, T.-W. (1987). Fatigue behaviour and damage development in woven fabric and hybrid fabric composites. In : Matthews, F.L., Buskell, N.C.R., Hodgkinson, J.M. and Morton, J. (eds.). Sixth International Conference on Composite Materials (ICCM-VI) \& Second European Conference on Composite Materials (ECCM-II) : Volume 4. Proceedings, 20-24 July 1987, London, UK, Elsevier, pp. 4.89-4.99.

[8] Schulte, K. (1984). Stiffness reduction and development of longitudinal cracks during fatigue loading of composite laminates. In : Cardon, A.H. and Verchery, G. (eds.). Mechanical characterisation of load bearing fibre composite laminates. Proceedings of the European Mechanics Colloquium 182, 29-31 August 1984, Brussels, Belgium, Elsevier, pp. 36-54.

[9] Fujii, T., Amijima, S. and Okubo, K. (1993). Microscopic fatigue processes in a plain-weave glass-fibre composite. COMPOSITES SCIENCE AND TECHNOLOGY, 49, 327-333.

[10] Pandita, S.D., Huysmans, G., Wevers, M. and Verpoest, I. (2000). Tensile fatigue behaviour of glass-plain weave fabric composites in the on and off-axis directions. Proceedings of the Fifth International Conference on Textile Composites, Leuven, Belgium, 18-20 September 2000.

[11] Shirazi, A and Varvani-Farahani, A. A Stiffness Degradation Based Fatigue Damage Model for FRP Composites of (0/theta) Laminate Systems. Applied Composite Materials 17 (2) Pages: 137-150 (2010)

[12] Giancane, S., Panella, F. W. and Dattoma, V. Characterization of fatigue damage in long fiber epoxy composite laminates. International Journal of Fatigue 32 (1) pages: 46-53 (2010)

[13] Taheri-Behrooz F., Shokrieh, M M. and Lessard, LB. Residual stiffness in cross-ply laminates subjected to cyclic loading. Composite Structures 85 (3) pages: 205-212 (2008)

[14] Sidoroff, F. and Subagio, B. (1987). Fatigue damage modelling of composite materials from bending tests. In : Matthews, F.L., Buskell, N.C.R., Hodgkinson, J.M. and Morton, J. (eds.). Sixth International Conference on Composite Materials (ICCM-VI) \& Second European Conference on Composite Materials (ECCM-II) : Volume 4. Proceedings, 20-24 July 1987, 
London, UK, Elsevier, pp. 4.32-4.39.

[15] Vieillevigne, S., Jeulin, D., Renard, J. and Sicot, N. (1997). Modelling of the fatigue behaviour of a unidirectional glass epoxy composite submitted to fatigue loadings. In : Degallaix, S., Bathias, C. and Fougères, R. (eds.). International Conference on fatigue of composites. Proceedings, 3-5 June 1997, Paris, France, La Société Française de Métallurgie et de Matériaux, pp. 424-430.

[16] Kawai, M. (1999). Damage mechanics model for off-axis fatigue behavior of unidirectional carbon fiber-reinforced composites at room and high temperatures. In: Massard, T. and Vautrin, A. (eds.). Proceedings of the Twelfth International Conference on Composite Materials (ICCM12). Paris, France, 5-9 July 1999, pp. 322.

[17] Hwang, W. and Han, K.S. (1986). Fatigue of composites - Fatigue modulus concept and life prediction. JOURNAL OF COMPOSITE MATERIALS, 20, 154-165.

[18] Hwang, W. and Han, K.S. (1986). Cumulative damage models and multi-stress fatigue life prediction. JOURNAL OF COMPOSITE MATERIALS, 20, 125-153.

[19] Whitworth, H.A. (1987). Modelling stiffness reduction of graphite epoxy composite laminates. JOURNAL OF COMPOSITE MATERIALS, 21, 362-372.

[20] Yang, J.N., Jones, D.L., Yang, S.H. and Meskini, A. (1990). A stiffness degradation model for graphite/epoxy laminates. JOURNAL OF COMPOSITE MATERIALS, 24, 753-769.

[21] Brøndsted, P., Andersen, S.I. and Lilholt, H. (1997). Fatigue damage accumulation and lifetime prediction of GFRP materials under block loading and stochastic loading. In : Andersen, S.I., Brøndsted, P., Lilholt, H., Lystrup, Aa., Rheinländer, J.T., Sørensen, B.F. and Toftegaard, H. (eds.). Polymeric Composites - Expanding the Limits. Proceedings of the 18th Risø International Symposium on Materials Science, 1-5 September 1997, Roskilde, Denmark, Risø International Laboratory, pp. 269-278.

[22] Brøndsted, P., Lilholt, H. and Andersen, S.I. (1997). Fatigue damage prediction by measurements of the stiffness degradation in polymer matrix composites. In : Degallaix, S., Bathias, C. and Fougères, R. (eds.). International Conference on fatigue of composites. Proceedings, 3-5 June 1997, Paris, France, La Société Française de Métallurgie et de Matériaux, pp. 370-377.

[23] Hochard, Ch. and Thollon, Y. A generalized damage model for woven ply laminates under static and fatigue loading conditions. International Journal of Fatigue 32 (1) pages:: 158165 (2010)

[24] Varvani-Farahani, A. and Shirazi, A. A fatigue damage model for (0/90) FRP composites based on stiffness degradation of 0 degrees and 90 degrees composite plies. Journal of Reinforced Plastics and Composites 26 (13) pages: 1319-1336 (2007)

[25] De Baere I., Van Paepegem W., Degrieck J., Sol H., Van Hemelrijck D. and Petreli A., Comparison of different identification techniques for measurement of quasi-zero Poisson's ratio of fabric reinforced laminates. Composites A 38 (9) pp. 2047-2054.

[26] Daggumati S, De Baere I., Van Paepegem W. Degrieck J. Xu J. Lomov SV and Verpoest I., Local Damage in 5-harness satin weave composite under static tension: Part I-Experimental Analysis. ACCEPTED for Composite Science and Technology

http://dx.doi.org/10.1016/j.compscitech.2010.07.003

[27] Daggumati S, Van Paepegem W. Degrieck J. Xu J. Lomov SV and Verpoest I., Local Damage in 5-harness satin weave composite under static tension: part II: meso-FE modelling.. ACCEPTED for Composite Science and Technology http://dx.doi.org/10.1016/j.compscitech.2010.07.002

[28] De Baere I, Van Paepegem W. and Degrieck J. Fusion bonding of carbon fabric reinforced polyphenylene sulphide. $14^{\text {th }}$ International Conference on Experimental Mechanics (ICEM-14), July 4 -9, 2010, Poitiers, France. 
http://dx.doi.org/10.1051/epjconf/20100608005

[29] De Baere I, Experimental and Numerical Study of Different Setups for Conducting and Monitoring Fatigue Experiments of Fibre-Reinforced Thermoplastics, Ph.D. thesis. Gent, Belgium, Ghent University, 2008. ISBN 978-90-8578-196-7

[30] De Baere I., Van Paepegem W. and Degrieck J., Comparison of the modified three-rail shear test and the $\left[\left(+45^{\circ},-45^{\circ}\right)\right]_{\text {ns }}$ tensile test for pure shear fatigue loading of carbon fabric thermoplastics. Fatigue and Fracture of Engineering Materials \& Structures. Vol. 31 (6) Pages: 414-427 (2008) 